Article

\title{
Simultaneous Voltammetric Determination of Gallic and Protocatechuic Acids in Mango Juice Using a Reduced Graphene Oxide-Based Electrochemical Sensor
}

\author{
Refat Abdel-Hamid ${ }^{1}$, Ahmed Bakr ${ }^{1}$, Emad F. Newair ${ }^{1, *}$ and François Garcia ${ }^{2}$ \\ 1 Unit of Electrochemistry Applications (UEA), Department of Chemistry, Faculty of Science, \\ Sohag University, Sohag 82524, Egypt; refat.abdelhamid@science.sohag.edu.eg (R.A.-H.); \\ ahmedbakr.science@gmail.com (A.B.) \\ 2 SPO, INRA, Montpellier Supagro, Montpellier University, UMR 1083, F-34060 Montpellier, France; \\ francois.garcia@umontpellier.fr \\ * Correspondence: emad.newair@science.sohag.edu.eg
}

Received: 1 October 2018; Accepted: 23 January 2019; Published: 6 February 2019

\begin{abstract}
A simple and sensitive reduced graphene oxide-modified glassy carbon electrode-based electrochemical sensor was used for the concomitant determination of gallic acid (GA) and protocatechuic (PA) acid. The prepared sensor showed a significant enhancement in synergetic electro-catalytic performance towards GA and PA oxidation. A good resolution of the voltammetry peaks was obtained and a method of square wave voltammetry was developed for detection. The modified electrode was characterized by electrochemical techniques. The optimal experimental parameters were considered. GA and PA exhibited a linear increase in the peak currents with their concentrations in the range from 20 to $144 \mu \mathrm{mol} \cdot \mathrm{L}^{-1}$ for GA and from 20 to $166 \mu \mathrm{mol} \cdot \mathrm{L}^{-1}$ for PA, with limits of detection $(\mathrm{S} / \mathrm{N}=3)$ of $30.8 \mu \mathrm{mol} \cdot \mathrm{L}^{-1}$ for GA and $10.2 \mu \mathrm{mol} \cdot \mathrm{L}^{-1}$ for PA. The sensor applicability was simultaneously tested for the analytical determination of GA and PA in mango juice and exhibited a robust functionality.
\end{abstract}

Keywords: voltammetry; reduced graphene oxide; electrochemical sensor; phenolic acids; mango juice

\section{Introduction}

Gallic acid (GA, 3,4,5-trihydroxybenzoic acid) and protocatechuic acid (PA, 3,4-dihydroxybenzoic acid), the most representative phenolic acids in fruits and vegetables, are strong antioxidants. They are present in a wide variety of fruits such as bananas, citrus fruits and mangoes as well as in green tea and several other plants. Recently, these phenolic acids have attracted great interest due to their scavenging ability against free radicals [1,2]. GA has received much attention because of its multiple biological and pharmaceutical properties, such as anti-inflammatory and antitumor activity, scavenging of free radicals and protection against cardiovascular diseases [3]. GA is mostly utilized in tanning, ink dyes, the manufacturing of paper, in the food industry, and in the drug trimethoprim in the pharmaceutical industry [4]. Therefore, the accurate determination of GA is a very important concern for human health. To date, many methods have been developed for the determination of GA, such as flow injection analysis [5], resonance light scattering [6], reversed phase high-performance liquid chromatography (HPLC) [7], high-pressure liquid chromatography coupled with quadrupole time-of-flight tandem mass spectrometry (HPLC-ESI-QTOF-MS/MS) [2] electrochemical sensors 
and nano-structured sensors [1,8-10]. Among these, electrochemical methods have received much attention lately, mainly due to their sensitivity, selectivity and simplicity.

Protocatechuic acid (3,4-dihydroxybenzoic acid, as the naturally occurring phenolic acid) is widely present in nearly all plants. PA is found in Spanish heath, dog rose, Korean spruce, gum-tree, the traditional Chinese medicine herb shensi, ferns, buckwheat, alder, onions, garlics and relatives, and Japanese peppers [11]. It is also found in pigmented onion scales [12], carrots, and mushrooms [13]. PA derivatives have potential antioxidant activity [14]. PA has been found to have several bioactivities such as antifungal, antihepatotoxic, anti-inflammatory, antioxidant [15], antibacterial [16], antidiabetic [17], anticancer [18], and antifibrotic [19] activities. Furthermore, it was found to be potent against avian influenza virus H9N2 infection [20]. PA was efficiently determined in grape juices using selective and rapid magnetic molecular imprinted solid phase extraction coupled with HPLC [21]. Trace PA from complex matrices was extracted and analyzed using high-capacity magnetic hollow porous molecularly imprinted polymers with HPLC. It was reported that the polymers that were used had high selectivity towards PA [22]. It was also determined electrochemically with a N-Butylpyridinium hexafluorophosphate ionic liquid modified carbon paste electrode, using the cyclic voltammetric method. Phosphate buffer solution ( $\mathrm{pH}$ 2.0) was selected as the supporting electrolyte. The proposed method was applied for its detection in juice [23].

The HPLC method is utilized for the simultaneous separation, identification, and quantification of phenolic compounds including GA and PA. The following techniques have been used for the simultaneous determination of GA and PA: High-performance liquid chromatography-photo diode array detector (HPLC-PDA) in Heliotropium thermophilum [24], HPLC-DAD-UV in crude grape cane extracts without pre-treatment [25], ultrahigh-performance liquid chromatography-photo diode array detector (UHPLC-PDA) in wines [26], and HPLC-PDA-ESI-MS in grapes [27]. HPLC techniques are highly selective, but their procedures are complex and time-consuming. Alternatively, electrochemical methods are highly selective, simple and sensitive. Various electrochemical determination methods have been performed for PA [23,28]. The electrochemical determination of catechin, PA, and L-lactic acid mixture has been developed in the presence of ferroceneboronic acid as an electrochemical probe [29]. The determination was performed using cyclic and differential pulse voltammetric methods on a glassy carbon electrode at $\mathrm{pH}$ 7.0. A novel efficient nanocomposite catalyst of $\mathrm{ZrO}_{2} / \mathrm{Co}_{3} \mathrm{O}_{4} / \mathrm{rGO} / \mathrm{FTO}$ was prepared by a reflux method and then characterized [30]. The nanocomposite electrode exhibits a synergistic catalytic effect towards the oxidation of GA, caffeic acid and PA. The proposed $\mathrm{ZrO}_{2} / \mathrm{Co}_{3} \mathrm{O}_{4} / \mathrm{rGO} / \mathrm{FTO}$ was applied successfully for the simultaneous determination of the three acids in fruit juice, rice and tea samples with satisfactory data. The major challenge in the simultaneous determination of GA and PA is the quantification of each in the presence of the other, since they are oxidized at almost similar potentials with poor sensitivity at the glassy carbon electrode. Voltammetric responses can overlap and this makes their simultaneous determination highly difficult. To overcome this problem, modification of the glassy carbon electrode (GCE) was developed using reduced graphene oxide (rGO).

Recently, graphene electrodes have received enormous interest. This is due to their unique properties, such as wide potential windows, inertness as a catalyst and good electro-catalytic activity. Thus, owing to these remarkable properties, they and their derivatives are promising candidates for the fabrication of electronic devices [30]. Among these derivatives, reduced graphene oxide is one of the best candidates. This is attributed to its reasonably reduced number of functionalities and many remaining electroactive sites. Reduced graphene oxide also offers a wide and interesting range of advantages, such as cheap and reliable preparation, large surface area, the possibility of functionalization, and good biocompatibility. Reduced graphene oxide composite is widely used as a building block of electrochemical sensors for the simultaneous determination of phenolic compounds. Mostly, reduced graphene oxide is prepared by the chemical reduction of graphene oxide, employing hazardous or corrosive reducing agents which bring impurities. As a result, the degradation of the electronic properties and weakening of the electrochemical performance of graphene occur due to 
the partial removal of oxygenated species. Thus, rGO is prepared using the green and convenient electrochemical reduction method. This method shows improved electrochemical performance and, in addition, a thin film of rGO can be prepared [31].

In this work, the electrochemical preparation of rGO elaborated an electrochemical sensor with satisfying selectivity, reproducibility and stability. The applicability of the sensor was tested for simultaneous quantification of gallic acid and protocatechuic acid in a real mango juice sample.

\section{Experimental}

\subsection{Chemicals}

All chemicals were of Analytical Reagents (AR) products. GA, PA, potassium hexacyanoferrate and the acids of buffer solutions were purchased from Sigma-Aldrich (Paris, France). Double-distilled water was used in this work. The $10.0 \mathrm{mM}$ aqueous stock solutions of GA and PA were freshly prepared before use and the measured solutions were obtained prepared by dilution. The test solution was degassed prior to and during the electrochemical experiments with pure nitrogen.

\subsection{Instruments}

Cyclic and square wave voltammetric experiments were performed utilizing an Autolab Potentiostat/Galvanostat (PGSTAT128N) (Eco Chemie BV, Utrecht, The Netherlands) coupled with NOVA 1.10 software (Metrohm Autolab B.V., Utrecht, The Netherlands). Three electrodes, the working (bare or modified glassy carbon electrodes), the reference $(\mathrm{Ag} / \mathrm{AgCl}$, aq. $\mathrm{KCl}, 3.5 \mathrm{M})$ and the auxiliary $\mathrm{Pt}$ wire electrodes, were used. The $\mathrm{pH}$ of the solutions was measured with a $\mathrm{pH}-$ meter (HI 2210, HANNA Instruments, Bucharest, Romania) using a combined $\mathrm{pH}$ reference electrode.

\subsection{Preparation of the $r G O / G C E$}

The surface of the glassy carbon electrode was polished with $0.05 \mu \mathrm{m}$ alumina in water using a polishing cloth until a mirror finish was achieved on the electrode surface and then it was rinsed thoroughly with double-distilled water. After that, the clean electrode was subjected to an ultrasonic bath of water and ethanol to assure the complete removal of any surface-bound impurities and then it was dried under ambient air conditions. Graphite oxide (GO) was prepared from natural graphite flakes by a modified version of the Hummer method [32]. The reduced graphene oxide (rGO)-modified electrode was prepared as follows: $1.0 \mathrm{mg} \cdot \mathrm{mL}^{-1} \mathrm{GO}$ powder was dispersed homogeneously in bi-distilled water by ultrasonication for $45 \mathrm{~min}$ to obtain a graphene oxide suspension. The rGO-modified electrode was then prepared by the electrochemical reduction of the GO suspension to form an insoluble thin layer of rGO on the surface of the GC electrode. This was conducted by repetitive cyclic voltammetry (CV) scanning from 0 to $-1.0 \mathrm{~V}$ at a scan rate of $50 \mathrm{mV} \cdot \mathrm{s}^{-1}$ in the degassed $0.04 \mathrm{M}$ Britton-Robinson buffer solution (B-R) ( $\mathrm{pH}$ 5.25) for 15 cycles. After that, the electrode was then carefully washed several times with water to remove the electrolyte and the monomer, and then dried at room temperature. The rGO/GCE was cleaned electrochemically after each measurement, using cyclic voltammetric scanning in a potential range of a 0.2 to $1.0 \mathrm{~V}$ window for 15 cycles at a scan rate of $50 \mathrm{mV} \cdot \mathrm{s}^{-1}$.

\subsection{Sample Preparation}

An amount of $2.0 \mathrm{~g}$ of pulp from golden yellow mango (The Governorate of Ismailia, Egypt) was first treated with $30 \%$ ethanol aqueous solution and then sonicated for $30 \mathrm{~min}$. The solution was later filtered through Whatman paper (No. 1). After removing the lipophilic impurities by filtration, $1.0 \mathrm{~mL}$ of the filtrate was diluted to $25 \mathrm{~mL}(\mathrm{~B}-\mathrm{R})(\mathrm{pH}$ 2.1) which was directly added to the electrochemical cell. The square wave voltammogram was then recorded. 


\section{Results and Discussion}

\subsection{Electrochemical Synthesis and Characterization of the rGO/GCE}

Figure 1 illustrates the repetitive CV cycles for the electrochemical reduction of GO-modified GCE. The voltammogram shows a cathodic reduction wave at around $-0.68 \mathrm{~V}$ in the first cycle which was ascribed to the reduction of the surface oxygen groups [33]. During the second cycle, the reduction wave is shifted negatively and its current starts to drop exceptionally. On progressing the CV scans, the decrease of current continues until a stable baseline current is reached. This indicates that the surface-oxygen species are successfully reduced.

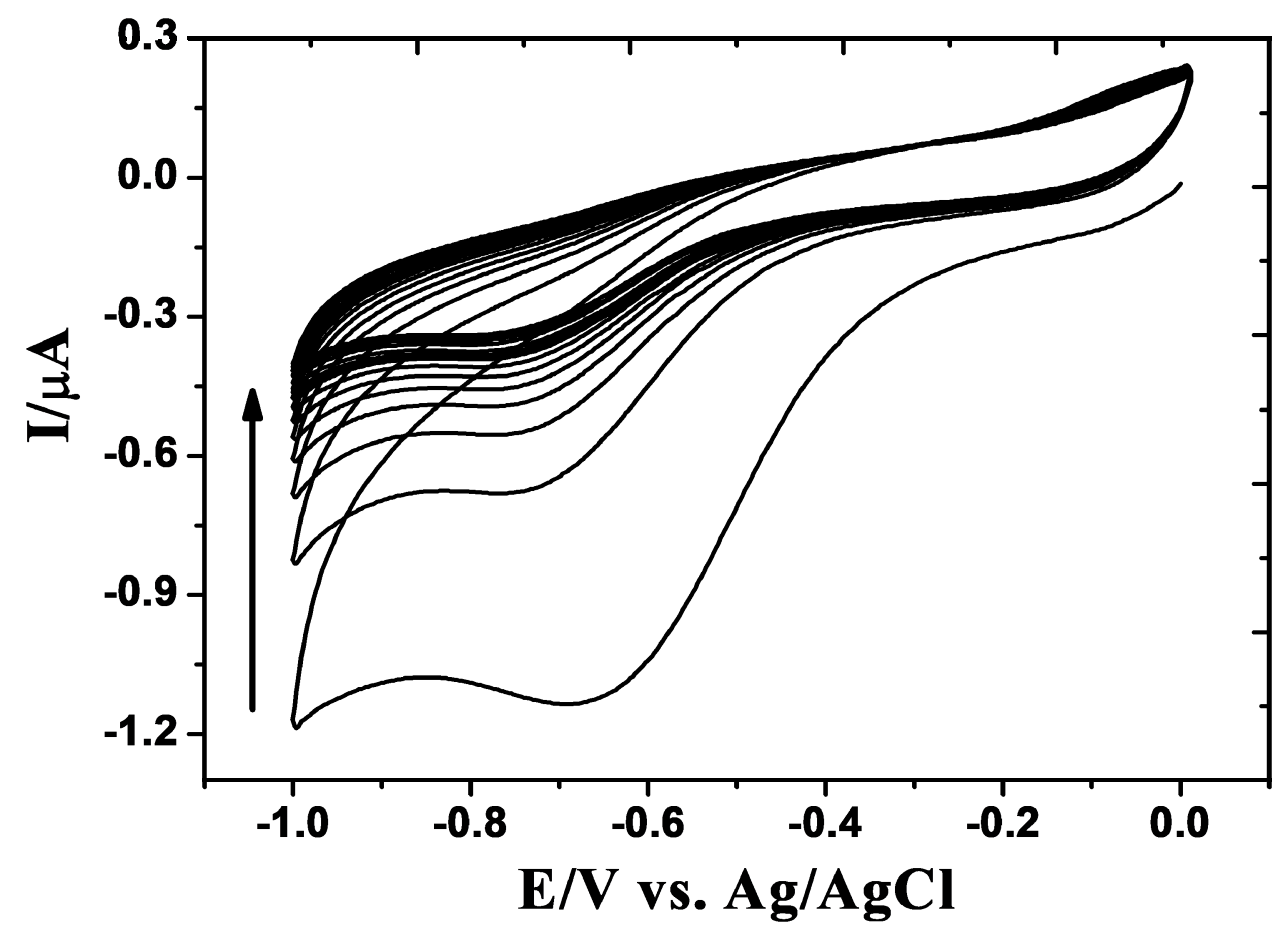

Figure 1. Repetitive cyclic voltammetry (CV) synthesis of the reduced graphene oxide/glassy carbon electrode (rGO/GCE) from graphene oxide in $0.04 \mathrm{M}$ Britton-Robinson buffer solution ( $\mathrm{pH} 5.25$ ) at a scan rate of $50 \mathrm{mV} \cdot \mathrm{s}^{-1}$.

In order to investigate the electrochemical properties of the concerned electrodes (the bare GCE and $\mathrm{rGO} / \mathrm{GCE})$, cyclic voltammetric measurements were performed using $\left[\mathrm{K}_{3} \mathrm{Fe}(\mathrm{CN})_{6}\right]$ as the electrochemical probe. Figure 2 presents the cyclic voltammograms obtained by the two studied electrodes of $1 \mathrm{mM}\left[\mathrm{K}_{3} \mathrm{Fe}(\mathrm{CN})_{6}\right]$ solution in $0.2 \mathrm{M} \mathrm{KCl}$ solution. On comparing the bare GCE with the $\mathrm{rGO} / \mathrm{GCE}$, the redox peak currents increase, whereas the peak-to-peak separation $\left(\Delta \mathrm{E}_{\mathrm{P}}\right)$ decreases using the rGO/GCE. The observed values of $\Delta \mathrm{E}_{\mathrm{P}}$ for the bare and modified GCEs are 172 and $83 \mathrm{mV}$, respectively. This clearly reveals that the electron transfer on the rGO surface is much easier than for the bare GCE. This might be due to the large surface area as well as the high electric conductivity of rGO. The electrochemical properties of the modified GC electrode were investigated by CV.

The cyclic voltammograms $(\mathrm{CVs})$ of $1.0 \mathrm{mM}\left[\mathrm{Fe}(\mathrm{CN})_{6}\right]^{3-/ 4-}$ solution were recorded at different scan rates (data not shown) in order to determine the effective active area of the subject electrode using the Randles-Sevcik equation [34]:

$$
I_{P}=\left(2.69 \times 10^{5}\right) n^{3 / 2} A^{1 / 2} C_{o} v^{1 / 2}
$$

where $I_{p}$ is the peak current $(A), n$ is the number of electrons in the electrode reaction $(n=1), A$ is the surface area of the electrode $\left(\mathrm{cm}^{2}\right), D_{o}$ is the diffusion coefficient $\left(D_{o}=7.6 \times 10^{-6} \mathrm{~cm}^{2} \cdot \mathrm{s}^{-1}\right), C_{o}$ is the 
concentration of $\left[\mathrm{Fe}(\mathrm{CN})_{6}\right]^{3-/ 4-}\left(\mathrm{C}_{\mathrm{o}}=1.0 \times 10^{-6} \mathrm{~mol} \cdot \mathrm{cm}^{-3}\right)$, and $v$ is the scan rate $\left(\mathrm{V} \cdot \mathrm{s}^{-1}\right)$. The active surface area was calculated to be 0.051 and $0.073 \mathrm{~cm}^{2}$ for the bare and modified electrodes, respectively. These results indicate that the active surface area of the modified GC electrode is increased by the presence of graphene $(\times 1.45$ more).

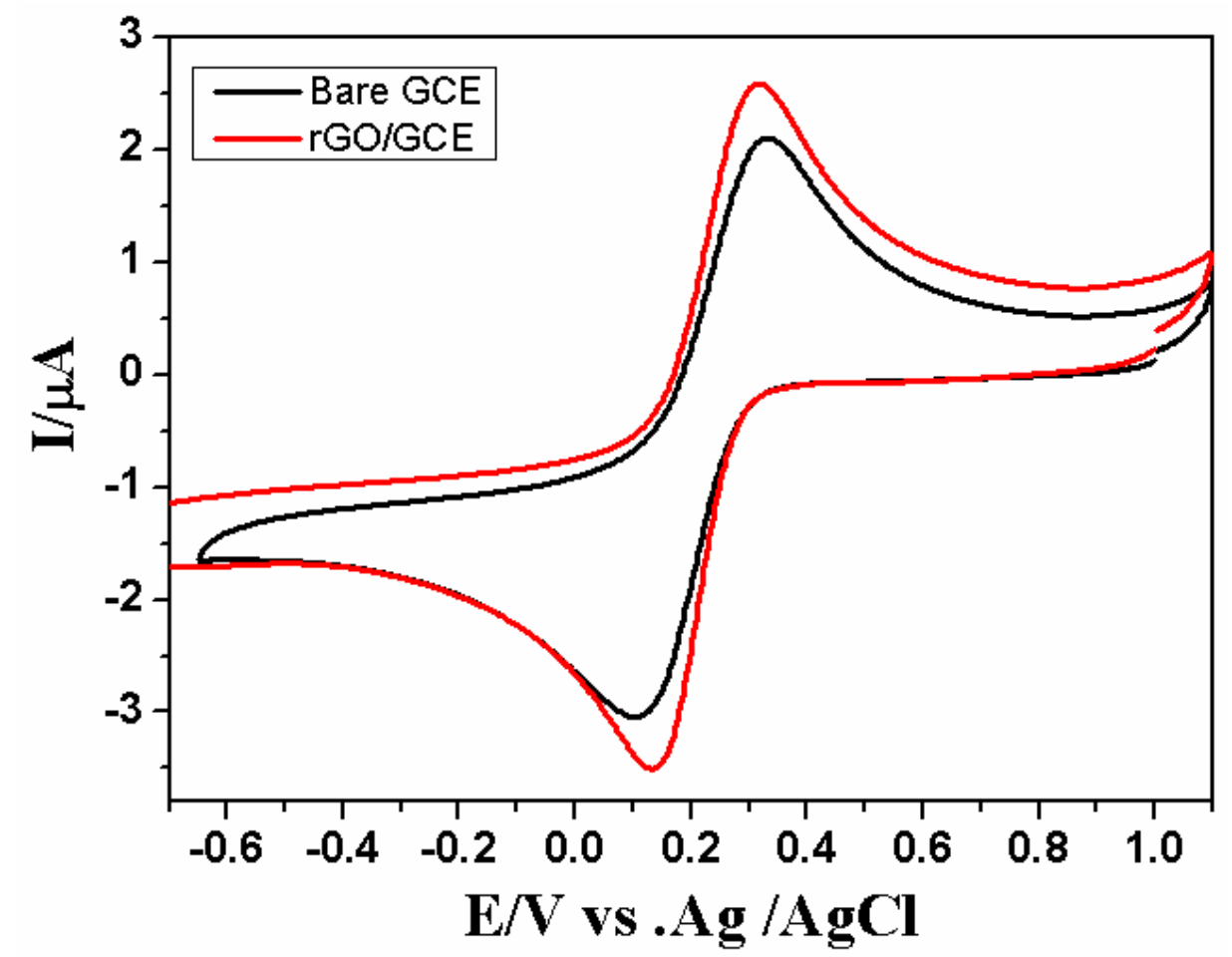

Figure 2. Cyclic voltammograms of $1.0 \mathrm{mmol} \cdot \mathrm{L}^{-1}\left[\mathrm{Fe}(\mathrm{CN})_{6}\right]^{3-/ 4-}$ in $0.2 \mathrm{~mol} \cdot \mathrm{L}^{-1} \mathrm{KCl}$ at the GCE and $\mathrm{rGO} / \mathrm{GCE}$ at a scan rate of $50 \mathrm{mV} \cdot \mathrm{s}^{-1}$.

\subsection{Electrochemical Oxidation of $G A$ and $P A$}

The electrochemical behavior of a solution mixture of $0.1 \mathrm{mM} \mathrm{GA}$ and PA was characterized at the GCE and rGO/GCE in Britton-Robinson buffer solution ( $\mathrm{pH}$ 2.1) at a scan rate of $50 \mathrm{mV} \cdot \mathrm{s}^{-1}$ (Figure 3). On one hand, no separation of the anodic peaks corresponding to the oxidation of the two acids was obtained at the bare GCE, making the determination of the individual concentration of the acids not possible from the obtained merged peaks. On the other hand, at the modified electrode (rGO/GCE), two oxidation peaks appeared at different potentials of 555 and $650 \mathrm{mV}$ with peaks separation $\left(\Delta \mathrm{E}_{\mathrm{p}}\right)$ of $95 \mathrm{mV}$, corresponding to the oxidation of GA and PA, respectively. The $\Delta \mathrm{E}_{\mathrm{p}}$ is large enough for the selective and simultaneous determination of GA and PA in their solution mixture. Furthermore, a remarkable increase in the peak current responses is observed with values of 12.58 and $21.44 \mu \mathrm{A}$ for GA and PA, respectively. This enhancement in the peak currents using the rGO/GCE is attributed to the high active surface area and to the excellent electrical conductivity of reduced graphene oxide, which increases the electron transfer kinetics between the electrode and the analytes. The obtained results confirm that the rGO/GCE enhances the oxidation of the two acids, making the simultaneous determination of GA and PA in the coexistence system feasible. Thus, the rGO/GCE-based electrochemical sensor was used for simultaneous determination with good selectivity as well as high sensitivity. 


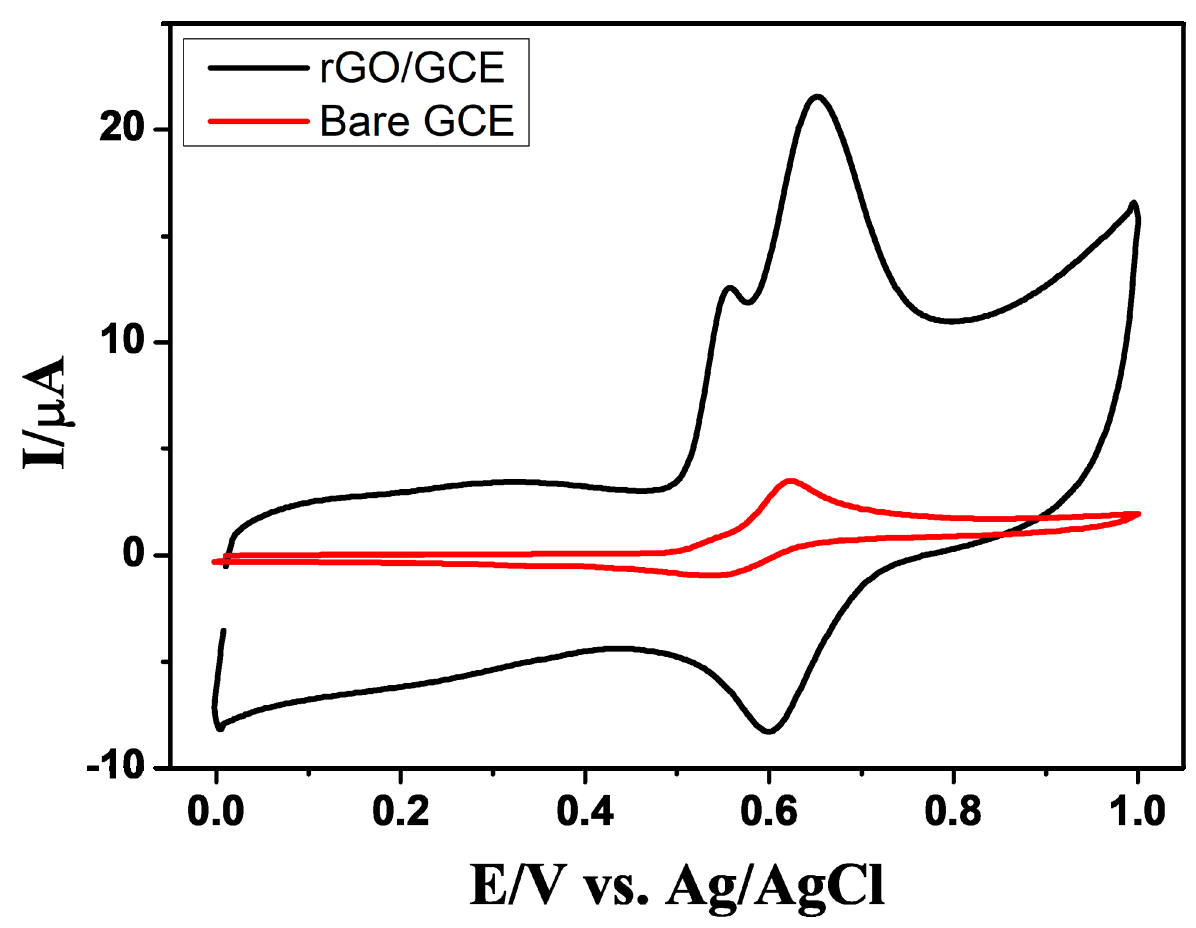

Figure 3. CVs of $0.10 \mathrm{mM} \mathrm{GA}$ and $0.10 \mathrm{mM}$ PA in B-R solution (pH 2.1) at a scan rate of $50 \mathrm{mV} \cdot \mathrm{s}^{-1}$.

\subsection{Effects of $\mathrm{pH}$ and Scan Rate on the Electrochemistry of GA and PA}

The evolution of the oxidation peak potentials for GA and PA versus $\mathrm{pH}$ was studied by cyclic voltammetry between $\mathrm{pH}$ values 2.1 and 6.1 of $\mathrm{B}-\mathrm{R}$ at the rGO/GCE (data not shown). It was revealed that the oxidation potentials of both acids were shifted negatively with the increasing $\mathrm{pH}$ of the solution. This shift is attributed to the participation of protons in the electrode reactions [35]. Linear relationships between the peak potential and the $\mathrm{pH}$ value were obtained with slope values of -52 and $-50 \mathrm{mV} / \mathrm{pH}$ for GA and PA, respectively. These slopes are close to the value for the Nernst system, i.e., $-59 \mathrm{mV} / \mathrm{pH}$ at $25^{\circ} \mathrm{C}$. This indicates that the overall electrode reaction proceeds through a transfer of an equal number of electrons and protons, two electrons and two protons as shown in Scheme 1 [36,37]. Also, the anodic peak currents of the two species decrease gradually as the $\mathrm{pH}$ increases. This trend could be explained as follows: at low $\mathrm{pH}$, the proton concentration is high and increases with the decreasing $\mathrm{pH}$ of the solution. This influences the ease of oxidation and enhances mass transport to the electrode surface and, in turn, increases the oxidation current. On further increase of the $\mathrm{pH}$, the current begins to decrease which may be due to the repulsive interaction between the positively charged electrode surface and the highly protonated GA and PA species. Consequently, a B-R buffer solution of $\mathrm{pH} 2.1$ was chosen for the sensitive determination in subsequent experiments.

The effect of the scan rate on the electrochemical peak current of GA and PA at the rGO/GCE in the range of 10 to $290 \mathrm{mV} \cdot \mathrm{s}^{-1}$ was investigated by CV (Figure 4). A linear log-log variation, log peak current $\left(\log \mathrm{I}_{\mathrm{p}}\right)$ versus $\log$ scan rate $(\log v)$ is obtained for both acids with a slope value of 0.48 and 0.41 for GA and PA, respectively. This indicates that the electrochemical oxidation of GA and PA is a diffusion-controlled process in nature. 

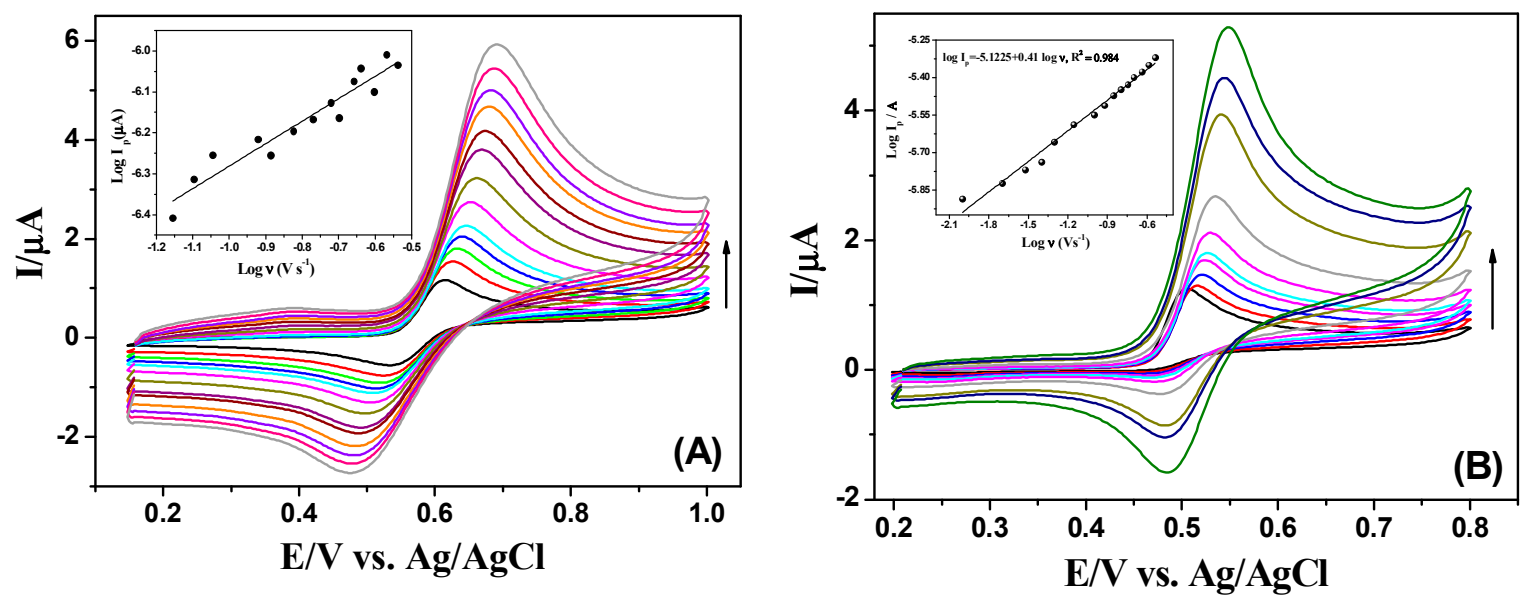

Figure 4. Cyclic voltammetry of the $\mathrm{rGO} / \mathrm{GCE}$ in $0.04 \mathrm{M} \mathrm{B}-\mathrm{R}(\mathrm{pH} 2.1)$ containing (A) $0.1 \mathrm{mM}$ GA and (B) $0.1 \mathrm{mM}$ PA at different scan rates $(10,20,30,40,50,80,90,120,150,170,190,200,230,270$ and $\left.290 \mathrm{mV} \cdot \mathrm{s}^{-1}\right)$.

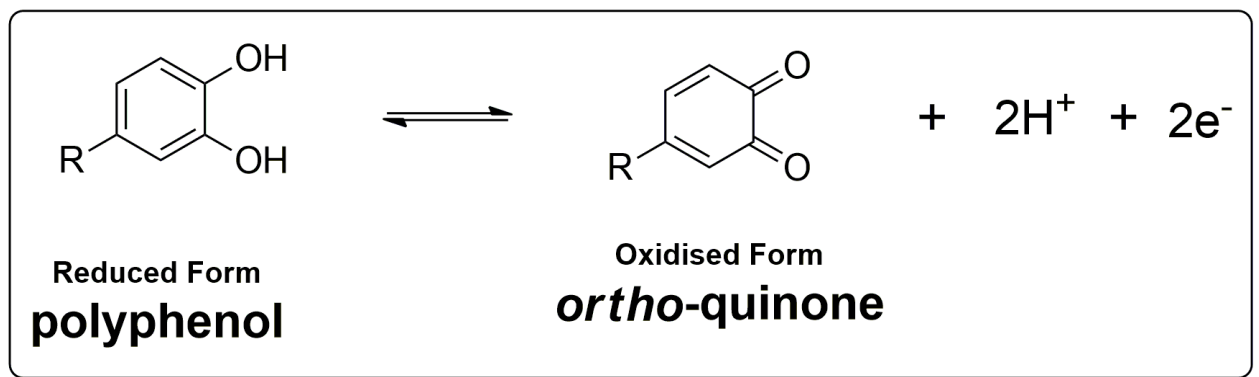

Scheme 1. The oxidation mechanism of polyphenol.

\subsection{Simultaneous Determination of $G A$ and $P A$}

The analytical performance of the subject sensor was studied using square wave voltammetry (SWV) for the simultaneous determination of GA and PA in their mixture, due to its higher sensitivity and better resolution than the CV (Figure 5). The key experimental parameters, such as frequency, amplitude and step potential, were optimized (not shown). The calibration plots of GA and PA show a linear increase of the current responses of the two species increasing their concentration (Figure 5). The linear regression equations are:

$$
\mathrm{I}_{\mathrm{p}}{ }^{\mathrm{a}}(\mu \mathrm{A})=0.005 \mathrm{C}_{\mathrm{GA}}(\mu \mathrm{M})+1.11 \times 10^{-7}\left(\mathrm{R}^{2}=0.95\right)
$$

and

$$
\mathrm{I}_{\mathrm{p}}{ }^{\mathrm{a}}(\mu \mathrm{A})=0.012 \mathrm{C}_{\mathrm{PA}}(\mu \mathrm{M})+2.27 \times 10^{-7}\left(\mathrm{R}^{2}=0.996\right)
$$

Furthermore, the linear variations range from 20 to $144 \mu \mathrm{mol} \cdot \mathrm{L}^{-1}$ for $\mathrm{GA}$ and from 20 to $166 \mu \mathrm{mol} \cdot \mathrm{L}^{-1}$ for PA, with detection limits $(\mathrm{S} / \mathrm{N}=3)$ of $30.8 \mu \mathrm{mol} \cdot \mathrm{L}^{-1}$ for $\mathrm{GA}$ and $10.2 \mu \mathrm{mol} \cdot \mathrm{L}^{-1}$ for PA. Also, the limits of quantitation (LOQ, $\mathrm{S} / \mathrm{N}=10$ ) obtained are $93.4 \mu \mathrm{mol} \cdot \mathrm{L}^{-1}$ for $\mathrm{GA}$ and $31.0 \mu \mathrm{mol} \cdot \mathrm{L}^{-1}$ for PA. These results illustrate that the proposed sensor possesses good analytical performance and the simultaneous quantification of GA and PA in the samples can be done successfully by the voltammetric method. 

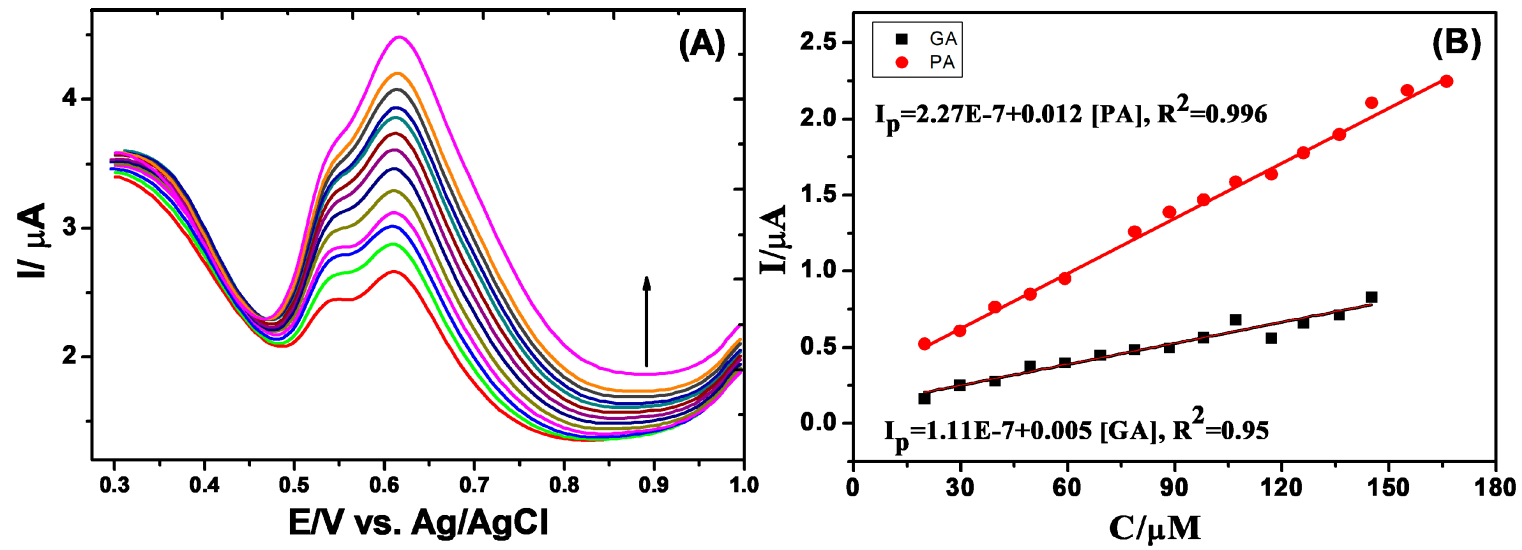

Figure 5. (A) SWV profiles at the rGO/GCE in 0.04 M B-R buffer ( $\mathrm{pH}$ 2.10) for different concentrations of GA and PA, and the (B) calibration plots.

\subsection{Interference, Repeatability and Stability Studies}

The interference of the 100-fold concentration of the coexisting substances (such as citric acid, tartaric acid, glucose, ascorbic acid and oxalic acid) on the concomitant determination of GA and PA $\left(0.1 \mathrm{mmol} \cdot \mathrm{L}^{-1}\right)$ in $\mathrm{B}-\mathrm{R}$ solution $(\mathrm{pH} 2.1)$ was investigated. Less than $5 \%$ current variation was observed, suggesting that no interference occurs. Moreover, the relative standard deviation (RSD) of the current corresponding oxidation peak was equal to $4.85 \%$ for 10 continuous measurements. In addition to that, the rGO/GCE activity remained constant during the minimum period of two weeks for the simultaneous determination of GA and PA. These results indicate that the rGO/GCE displayed good stability and repeatability concerning the detection of the subject analytes.

Finally, the stability of the modified electrode was measured daily for 21 days. The peak current remained $94 \%$ of its original value during the three weeks, showing that the rGO/GCE electrochemical sensor has very good stability.

\subsection{Analysis of Real Samples}

The GA and PA content in a commercial mango sample was determined with the developed square wave voltammetric method in order to validate the use of the sensor based on the rGO/GCE for the simultaneous determination of GA and PA in a real sample. The standard addition method was employed in order to quantify the quantities of the gallic and protocatechuic acids in the sample with standard solutions of the acids using the earlier described method, considering the optimal parameters, and then the voltammograms were recorded. The obtained results are shown in Figure 6 . In these experiments, successive amounts of standard GA and PA solutions were added to the test solution. The total content of GA and PA in the dried commercial mango sample is expressed as milligrams of GA and PA equivalents. It was estimated to be $2.4 \mathrm{mg} \cdot \mathrm{g}^{-1}$ dry weight (DW) and $5.4 \mathrm{mg} \cdot \mathrm{g}^{-1} \mathrm{DW}$ for GA and PA, respectively.

\section{Conclusions}

A reliable and simple electrochemical method was presented in this study for the simultaneous determination of gallic acid and protocatechuic acid using the electrochemically synthesized reduced graphene oxide. The rGO/GCE exhibited much improved electrocatalytic oxidation behavior and good resolution towards the selective oxidation of these acids. The outstanding electrocatalytic properties of the $\mathrm{rGO} / \mathrm{GCE}$ probably make it a promising candidate for the sensitive and selective electrochemical sensing of these acids in fruit juice (mango). 


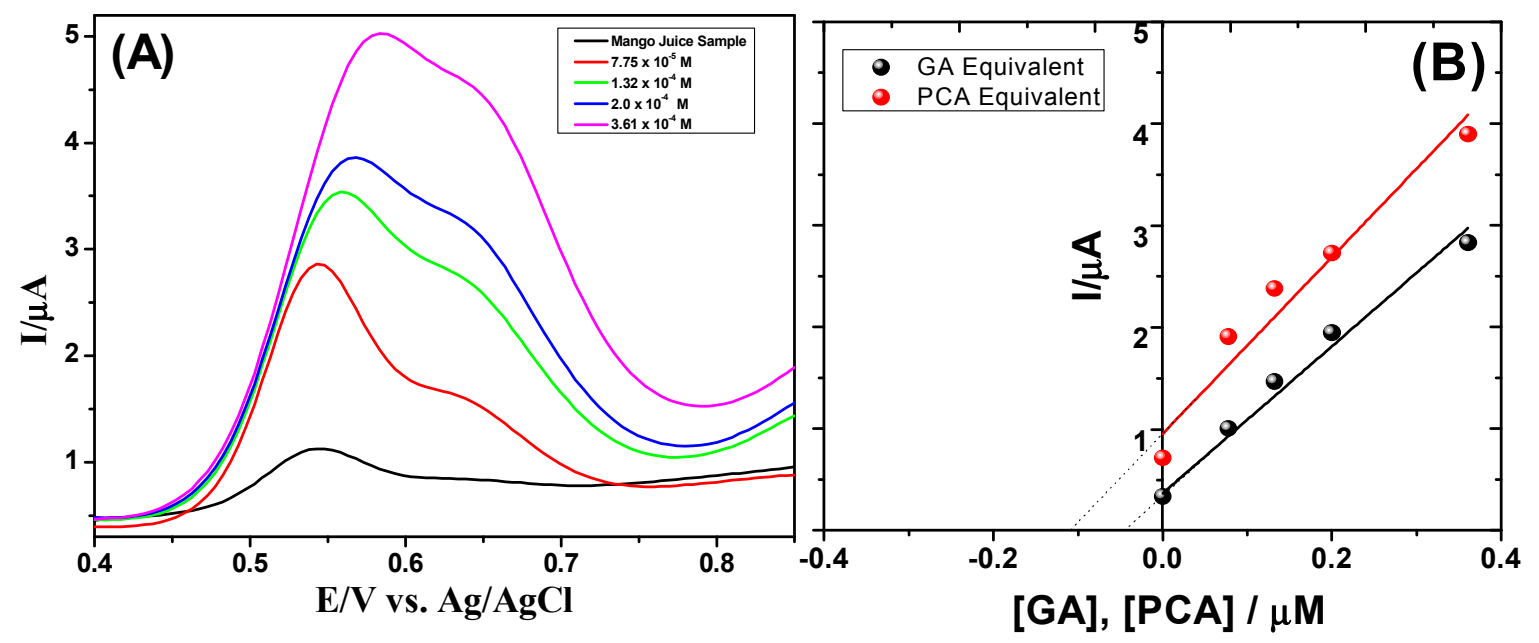

Figure 6. (A) Square wave voltammograms of a mango sample in B-R solution in optimal conditions: pH 2.1 at frequency $25 \mathrm{~Hz}$ and successive additions of standards GA and PA; (B) Standard addition plots of GA and PA in a mango sample.

Author Contributions: The following statement illustrates the individual's contributions of each author. E.F.N. and R.A.-H. have set up the conceptualization, while A.B. and E.F.N. have performed the methodology, software, validation, formal analysis, investigation, and data curation. R.A.-H. has written the original draft preparation, while F.G. and E.F.N. have performed the writing-review \& editing as well as supervision.

Funding: This research was funded by the Science \& Technology Development Fund [STDF], Egypt, grant number [5361].

Conflicts of Interest: The authors declare no conflicts of interest.

\section{References}

1. Ghaani, M.; Nasirizadeh, N.; Ardakani, S.A.Y.; Mehrjardi, F.Z.; Scampicchiod, M.; Farris, S. Development of an electrochemical nanosensor for the determination of gallic acid in food. J. Anal. Methods 2016, 8, 1103-1110. [CrossRef]

2. Kumar, S.; Singha, A.; Kumar, B.; Pharmaceut, J. Identification and characterization of phenolics and terpenoids from ethanolic extracts of Phyllanthus species by HPLC-ESI-QTOF-MS/MS. J. Pharm. Anal. 2017, 7, 214-222. [CrossRef] [PubMed]

3. Mudnic, I.; Modun, D.; Rastija, V.; Vukovic, J.; Brizic, I.; Katalinic, V.; Kozina, B.; Medic-Saric, M.; Boban, M. Antioxidative and vasodilatory effects of phenolic acids in wine. Food Chem. 2010, 119, 1205-1210. [CrossRef]

4. Sarjit, A.; Wang, Y.; Dykes, G.A. Antimicrobial activity of gallic acid against thermophilic Campylobacter is strain specific and associated with a loss of calcium Ions. Food Microbiol. 2015, 46, 227-233. [CrossRef] [PubMed]

5. Phakthong, W.; Liawruangrath, B.; Liawruangrath, S. Determination of gallic acid with rhodanine by reverse flow injection analysis using simplex optimization. Talanta 2014, 130, 577-584. [CrossRef] [PubMed]

6. Wang, H.; Chen, D.; Wel, Y.; Chang, Y.; Zhao, J. A Simple and Sensitive Assay of Gallic Acid Based on Localized Surface Plasmon Resonance Light Scattering of Silver Nanoparticles through Modified Tollens Process. Anal. Sci. 2011, 27, 937-941. [CrossRef] [PubMed]

7. Narumi, K.; Sonoda, J.I.; Shiotani, K.; Shigeru, M.; Shibata, M.; Kawachi, A.; Tomishige, E.; Sato, K.; Motoya, T. Simultaneous detection of green tea catechins and gallic acid in human serum after ingestion of green tea tablets using ion-pair high-performance liquid chromatography with electrochemical detection. J. Chromatogr. B 2014, 945, 147-153. [CrossRef] [PubMed]

8. Abdel-Hamid, R.; Newair, F.E. Adsorptive stripping voltammetric determination of gallic acid using an electrochemical sensor based on polyepinephrine/glassy carbon electrode and its determination in black tea sample. J. Electroanal. Chem. 2013, 704, 32-37. [CrossRef] 
9. Sundaram, S.; Jagannathan, M.; Kadir, M.R.A.; Palanivel, S.; Hadibarata, T.; Yusoff, A.R.M. A new electro-generated o-dianisidine derivative stabilized MWCNT-modified GCE for low potential gallic acid detection. RSC Adv. 2015, 5, 45996-46006. [CrossRef]

10. Sum, Y.L.; Chen, S.H. Sensitive and selective determination of gallic acid in green tea samples based on an electrochemical platform of poly(melamine) film. Anal. Chim. Acta 2015, 901, 41-50. [CrossRef]

11. Hur, J.M.; Park, J.G.; Yang, K.H.; Park, J.C.; Park, J.R.; Chun, S.S.; Choi, J.S.; Choi, J.W. Effect of Methanol Extract of Zanthoxylum piperitum Leaves and of Its Compound, Protocatechuic Acid, on Hepatic Drug Metabolizing Enzymes and Lipid Peroxidation in Rats. Biosci. Biotechnol. Biochem. 2003, 67, 945-950. [CrossRef] [PubMed]

12. Vitaglione, P.; Donnarumma, G.; Napolitano, A.; Galvano, F.; Gallo, A.; Scalfi, L.; Fogliano, V. Protocatechuic acid is the major human metabolite of cyanidin-glucosides. J. Nutr. 2007, 137, 2043-2048. [CrossRef] [PubMed]

13. Kakkar, S.; Bais, S. A Review on Protocatechuic Acid and Its Pharmacological Potential. ISRN Pharmacol. 2014, 2014, 952943. [CrossRef] [PubMed]

14. Li, X.; Wang, X.; Chen, D.; Chen, S. Antioxidant Activity and Mechanism of Protocatechuic Acid in vitro. Funct. Foods Health Dis. 2011, 1, 232-244.

15. Vari, R.; D'Archivio, M.; Filesi, C.; Carotenuto, S.; Scazzocchio, B.; Santangelo, C.; Giovannini, C.; Masella, R. Protocatechuic acid induces antioxidant/detoxifying enzyme expression through JNK-mediated Nrf2 activation in murine macrophages. J. Nutr. Biochem. 2011, 22, 409-417. [CrossRef] [PubMed]

16. Chao, C.Y.; Yin, M.C. Antibacterial effects of roselle calyx extracts and protocatechuic acid in ground beef and apple juice. Foodborne Pathog. Dis. 2009, 6, 201-206. [CrossRef] [PubMed]

17. Scazzocchio, B.; Var, R.; Filesi, C.; D’Archivio, M.; Santangelo, C.; Giovannini, C.; Iacovelli, A.; Silecchia, G.; Volti, G.L.; Galvano, F. Cyanidin-3-O- $\beta$-glucoside and protocatechuic acid exert insulin-like effects by upregulating PPAR $\gamma$ activity in human omental adipocytes. Diabetes 2011, 60, 2234-2244. [CrossRef] [PubMed]

18. Tanaka, T.; Tanaka, T.; Tanaka, M. Potential cancer chemopreventive activity of protocatechuic acid. J. Exp. Clin. Med. 2011, 3, 27-33. [CrossRef]

19. Li, C.; Jiang, W.; Zhu, H.; Hou, J. Antifibrotic effects of protocatechuic aldehyde on experimental liver fibrosis. Pharm. Biol. 2012, 50, 413-419. [CrossRef] [PubMed]

20. Ou, C.; Shi, N.; Yang, Q.; Zhang, Y.; Wu, Z.; Wang, B.; Compans, R.W.; He, C. Protocatechuic acid, a novel active substance against avian Influenza virus H9N2 infection. PLoS ONE 2014, 9, e111004. [CrossRef] [PubMed]

21. Xie, L.; Guo, J.; Zhang, Y.; Shi, S. Efficient Determination of Protocatechuic Acid in Fruit Juices by Selective and Rapid Magnetic Molecular Imprinted Solid Phase Extraction Coupled with HPLC. J. Agric. Food Chem. 2014, 62, 8221-8228. [CrossRef] [PubMed]

22. Li, H.; Hu, X.; Zhang, Y.; Shi, S.; Jiang, X.; Chen, X. High-capacity magnetic hollow porous molecularly imprinted polymers for specific extraction of protocatechuic acid. J. Chromatogr. A 2015, 1404, 21-27. [CrossRef] [PubMed]

23. Sun, W.; Jiang, Q.; Xi, M.; Jiao, K. Determination of 3,4-dihydroxybenzoic acid by electrocatalytic oxidation at an ionic liquid modified electrode. Microchim. Acta 2009, 166, 343-348. [CrossRef]

24. Yildirim, S.; Kadioğlu, A.; Sağlam, A.; Yaşar, A. Determination of phenolic acids and rutin in Heliotropium thermophilum by high-performance liquid chromatography with photodiode array detection. Instrum. Sci. Technol. 2017, 45, 35-48. [CrossRef]

25. Zhang, A.; Wan, L.; Wu, C.; Fang, Y.; Han, G.; Li, H.; Zhang, Z.; Wang, H. Simultaneous Determination of 14 Phenolic Compounds in Grape Canes by HPLC-DAD-UV Using Wavelength Switching Detection. Molecules 2013, 18, 14241-14257. [CrossRef] [PubMed]

26. Silva, C.L.; Pereiraa, J.; Woutera, V.G.; Giro, C.; Câmara, J.S. A fast method using a new hydrophilic-lipophilic balanced sorbent in combination with ultra-high-performance liquid chromatography for quantification of significant bioactive metabolites in wines. Talanta 2011, 86, 82-90. [CrossRef] [PubMed]

27. Nicoleti, I.; Bello, C.; de Rossi, A.; Corrandini, D. Identification and Quantification of Phenolic Compounds in Grapes by HPLC-PDA-ESI-MS on a Semimicro Separation Scale. J. Agric. Food Chem. 2008, 56, 8801-8808. [CrossRef] [PubMed] 
28. Xie, L.; Guo, J.; Zhang, Y.; Hua, Y.; You, Q.; Shi, S. Novel molecular imprinted polymers over magnetic mesoporous silica microspheres for selective and efficient determination of protocatechuic acid in Syzygium aromatic. Food Chem. 2015, 178, 18-25. [CrossRef] [PubMed]

29. Shi, W.; Wang, J.; Zhu, L.; Cai, M.; Du, X. Electrochemical determination of catechin, protocatechuic acid, and L-lactic acid based on voltammetric response of ferroceneboronic acid. J. AOAC Int. 2014, 97, 1742-1745. [CrossRef] [PubMed]

30. Puangjan, A.; Chaiyasith, S. An efficient $\mathrm{ZrO}_{2} / \mathrm{Co}_{3} \mathrm{O}_{4} /$ reduced graphene oxide nanocomposite electrochemical sensor for simultaneous determination of gallic acid, caffeic acid and protocatechuic acid natural antioxidants. Electrochim. Acta 2014, 211, 273-288. [CrossRef]

31. Liscio, A.; Veronese, G.P.; Treossi, E.; Suriano, F.; Rosella, F.; Bellani, V.; Rizzoli, R.; Samori, P.; Palermo, V. Charge transport in graphene-polythiophene blends as studied by Kelvin Probe Force Microscopy and transistor characterization. J. Mater. Chem. 2011, 21, 2924-2931. [CrossRef]

32. Yang, L.; Liu, D.; Huang, J.; You, T. Simultaneous determination of dopamine, ascorbic acid and uric acid at electrochemically reduced graphene oxide modified electrode. Sens. Actuators B 2014, 193, 166-172. [CrossRef]

33. Roghani-Mamaqani, H.; Haddadi-Asl, V.; Khezri, K.; Salami-Kalajahi, M. Polystyrene-grafted graphene nanoplatelets with various graft densities by atom transfer radical polymerization from the edge carboxyl groups. RSC Adv. 2014, 4, 24439-24452. [CrossRef]

34. Yang, J.; Deng, S.; Lei, J.; Jub, H.; Gunasekarana, S. Electrochemical synthesis of reduced graphene sheet-AuPd alloy nanoparticle composites for enzymatic biosensing. Biosens. Bioelectron. 2011, 29, 159-166. [CrossRef] [PubMed]

35. Wang, S.F.; Xie, F.; Hu, R.F. Electrochemical study of brucine on an electrode modified with magnetic carbon-coated nickel nanoparticles. Anal. Bioanal. Chem. 2007, 387, 933-939. [CrossRef] [PubMed]

36. Abdel-Hamid, R.; Newair, E.F. Electrochemical behavior of antioxidants: I. Mechanistic study on electrochemical oxidation of gallic acid in aqueous solutions at glassy-carbon electrode. J. Electroanal. Chem. 2011, 657, 107-112. [CrossRef]

37. Hotta, H.; Ueda, M.; Nagano, S.; Tsujino, Y.; Koyama, J.; Osakai, T. Mechanistic Study of the Oxidation of Caffeic Acid by Digital Simulation of Cyclic Voltammograms. J. Anal. Biochem. 2002, 303, 66-72. [CrossRef] [PubMed] 